\title{
Arctic sea-ice conditions and the distribution of solar radiation during summer
}

\author{
Donald K. Perovich, Walter B. Tucker, III \\ U.S. Army Cold Regions Research and Engineering Laboratory, 72 Lyme Road, Hanover, NH 03755, U.S.A.
}

\begin{abstract}
Understanding the interaction of solar radiation with the ice cover is critical in determining the heat and mass balance of the Arctic ice pack, and in assessing potential impacts due to climate change. Because of the importance of the ice-albedo feedback mechanism, information on the surface state of the ice cover is needed. Observations of the surface state of sea ice were obtained from helicopter photography missions made during the 1994 Arctic Ocean Section cruise. Photographs from one flight, taken during the height of the melt season (31 July 1994) at $76^{\circ} \mathrm{N}, 172^{\circ} \mathrm{W}$, were analyzed in detail. Bare ice covered $82 \%$ of the total area, melt ponds $12 \%$, and open water $6 \%$. There was considerable variability in these area fractions on scales $<1 \mathrm{~km}^{2}$. Sample areas $>2-3 \mathrm{~km}^{2}$ gave representative values of ice concentration and pond fraction. Melt ponds were numerous, with a number density of 1800 ponds $\mathrm{km}^{-2}$. The melt ponds had a mean area of $62 \mathrm{~m}^{2}$, a median area of $14 \mathrm{~m}^{2}$, and a size distribution that was well fit by a cumulative lognormal distribution. While leads make up only a small portion of the total area, they are the source of virtually all of the solar energy input to the ocean.
\end{abstract}

\section{INTRODUCTION}

Results from general circulation models (GCMs) indicate that the Arctic sea-ice cover may exert a strong influence on global climate and may also be a sensitive indicator of climate change. Because of this, a knowledge of the heat and mass balance of the Arctic ice pack is critical in assessing potential impacts due to climate change. The ice-albedo feedback mechanism is of particular importance, since the positive feedback between ice conditions and albedo may help to amplify small changes in climatic forcing (Ingram and others, 1989; Manabe and others, 1991; Rind and others, 1995). To examine the interaction of solar radiation with the ice cover on a large scale, information is needed regarding the relative areas of different ice types as well as the optical properties of the ice types.

Sea-ice surface conditions undergo large changes during the seasonal transition from spring to summer. During most of the year there is a homogeneous, highly reflective, snowcovered surface with little open water present. Once melt begins, this homogeneous surface transforms into a variegated surface comprising melting snow, bare ice, melt ponds and leads. Attendant with this transformation is a significant decrease in the areally averaged, wavelength-integrated albedo from approximately 0.8 to 0.5 .

Melt ponds are a critical element in the heat balance of the summer sea-ice cover (Ebert and Curry, 1993; Moritz and others, 1993; Ebert and others, 1995). Wavelengthintegrated albedos for melt ponds range from 0.2 to 0.4 (Grenfell and Maykut, 1977; Grenfell and Perovich, 1984), and they can absorb as much as four times more solar radiation than bare ice or snow-covered ice. As melt ponds form, the albedo decreases and the amount of energy absorbed in the ice increases, thereby accelerating melting and providing a potential positive feedback mechanism. Field obser- vations indicate that both the albedo of melt ponds, and the fractional area covered by them, can vary over a wide range and are continually changing during the melt season. Recent studies (Morassutti and LeDrew, 1995; Derksen and others, 1996) have examined the physical characteristics and the albedo of melt ponds on first-year ice. More information is needed regarding the distribution of the solar radiation deposited in a melt pond among reflection, absorption in the pond, absorption in the underlying ice and transmission to the ocean.

Significant amounts of solar radiation are input to the ocean through leads. An open lead absorbs over $90 \%$ of the incident solar radiation. Here, too, there is the potential for positive feedback, with solar radiation deposited in leads causing lateral melting, thereby increasing the size of the leads and consequently the input solar radiation to the region. The disposition of this energy among lateral melting, bottom melting, and warming of the water is a key issue. Earlier theoretical studies of summer leads (Zubov, 1945; Langleben, 1972) assumed that all of the solar energy deposited in a lead contributed to the lateral melting of the ice. More recent work (Perovich, 1983; Maykut and Perovich, 1987; Perovich and Maykut, 1990; Steele, 1992; Maykut and McPhee, 1995; Schramm and Curry, 1994) has indicated that this is not the case, and that the magnitude and the character of ice decay are sensitive to how this heat is distributed among lateral melting, bottom ablation, and storage in the ocean.

To assess the impact of ponds and leads on the heat and mass balance of the ice cover, we need to understand the physical processes of individual leads and ponds, and we need information on the relative area of ice, ponds and leads and on the number and size of ponds and leads. In this paper the focus is on the second issue, and we discuss results from aerial photographs made during the 1994 Arctic 
Ocean Section cruise. These photographs were analyzed to determine the relative areas of ice, ponds and leads; the number, shape and size distribution of melt ponds; and the size of the aggregate scale for ice concentration and pond fraction. Results from a single day are examined in detail and compared to data from two other days. Computed estimates of the disposition of incident solar radiation among reflection, absorption and transmission are presented for these three cases.

\section{EXPERIMENT AND METHODS}

The Arctic Ocean Section experiment was a two-icebreaker transect across the Arctic Basin involving the CCGS Louis S. St. Laurent and the USCGC Polar Sea (Aagaard and others, 1996). The route was from the Bering Sea north to the Pole and south to Fram Strait. During this cruise we made a series of measurements investigating the optical and physical properties of the sea-ice cover. The cruise duration was from 25 July to 6 September 1994, encompassing the summer melt season and the onset of fall freeze-up. The focus of our work was on studying the temporal and spatial variability of ice conditions, physical properties and albedos. As part of this effort, ten helicopter photography flights, each roughly $150 \mathrm{~km}$ long, were made to characterize icesurface conditions and to extend surface-based measurements to the large scale.

A Nikon $35 \mathrm{~mm}$ camera complete with motor drive and a 250 frame roll of film was used to take 100-200 color photographs during each flight. A $50 \mathrm{~mm}$ lens was used, with an exposure time of $1 / 1000$ of a second and an aperture setting of 2.8 or 4.0 , depending on incident light levels. The focus was always set at infinity. The camera was mounted in a weather-protected box that was attached to the floor of the Coast Guard HH 65A helicopter. The camera was mounted to look vertically downward, and was oriented so that the longer side of the film was aligned with the direction of flight. The standard flight path consisted of a modified box pattern around the ship, with four 25 and two $50 \mathrm{~km}$-long legs. Low, overcast conditions and fog were common during the experiment, limiting when flights could occur and restricting the maximum altitude to between 400 and $700 \mathrm{~m}$.

The photographs were developed and enlarged to $12.7 \times 17.8 \mathrm{~cm}$. They were then digitized using a flatbed scanner at a spatial resolution of 48 pixels $\mathrm{cm}^{-1}$ with 24 bit color. The use of color was critical in distinguishing between melt ponds and bare gray ice. These digital images were then processed on a personal computer using standard com- mercial software (Optimas, 1995). Using the full range of color it was possible to partition the surface in each image into four categories: bare and snow-covered ice, ponded ice, frozen ponds, and open water. Once an image was partitioned, the fractional area of each surface type was calculated to the nearest per cent. Further analysis was performed to determine the number of melt ponds and to compute the pond area and shape factor. Due to the low altitude it was not possible to determine the floe-size distribution. However, the total lead perimeter was computed for each image. The lead perimeter and the amount of open water are significant parameters in determining the amount of lateral melting (Perovich, 1983; Maykut and Perovich, 1987; Steele, 1992).

\section{RESULTS AND DISCUSSION}

Most of this paper will concentrate on a single flight made on 31 July 1994 at $76^{\circ} \mathrm{N}, 172^{\circ} \mathrm{W}$ (Table 1). This flight was selected for in-depth study since the melt season was well advanced and the surface illumination was excellent with no fog or low clouds. 160 photographs were taken from an altitude of $610 \mathrm{~m}$ along a $142 \mathrm{~km}$ flight track. Each photograph covered an area of $440 \times 290 \mathrm{~m}$, providing roughly $50 \%$ coverage along the length of the flight path. The total area covered by these photographs was $20.5 \mathrm{~km}^{2}$.

Several qualitative observations regarding the surface state of the ice, and melt ponds in particular, can be made by visually examining the images. The aerial photograph in Figure 1 provides representative examples of some of the general features of melt ponds. There were numerous melt ponds present along the entire flight path. The largest ponds actually consisted of several ponds connected by small tributaries. Ridges often had ponds associated with them, running parallel to the ridge. Melt ponds were many different shades of blue, from a light, whitish sky-blue to a dark bluegreen. A very few ponds had melted through and appeared black, like the leads. There were some pond-like features at the edges of floes. These features are typically a result of lateral melting and erosion. Optically, they are similar to melt ponds, though they differ hydrologically from ponds since they are directly connected to the ocean. These edges are classified as ponds in our analysis.

The relative areas of ice, ponds and leads along the flight path are plotted in Figure 2. There is a high degree of smallscale variability evident. The large discrete jumps of $30-$ $60 \%$ in lead area are associated with the flight path crossing leads that were a few hundred $\mathrm{m}$ wide. Pond coverage fluc-

Table 1. Summary of results from flights on 31 July, 13 August and 18 August 1994. The image size and total area have units of $\mathrm{km}^{2}$. Percent areas are reported for ice $\left(A_{\mathrm{i}}\right)$, frozen ponds $\left(A_{\mathrm{fp}}\right)$, melt ponds $\left(A_{\mathrm{p}}\right)$ and leads $\left(A_{\mathrm{w}}\right)$. Areally averaged values for the partitioning of the incident solar radiation are reported in terms of the percent reflected $(\alpha)$, absorbed in the ice $(A)$ and deposited in the ocean $(D)$

\begin{tabular}{|c|c|c|c|c|c|c|c|c|c|c|c|c|c|}
\hline Date & Latitude & Longitude & $\begin{array}{l}\text { Altitude } \\
\mathrm{m}\end{array}$ & Image size & Frames & Total area & $A_{\mathrm{i}}$ & $A_{\mathrm{fp}}$ & $A_{\mathrm{p}}$ & $A_{\mathrm{w}}$ & $a$ & $A$ & $D$ \\
\hline 31 July & $76^{\circ} 02^{\prime} \mathrm{N}$ & $171^{\circ} 44^{\prime} \mathrm{W}$ & 610 & 0.13 & 160 & 20.5 & 82 & 0 & 12 & 6 & 59 & 34 & 7 \\
\hline 13 August & $84^{\circ} 06^{\prime} \mathrm{N}$ & $174^{\circ} 58^{\prime} \mathrm{E}$ & 460 & 0.07 & 24 & 1.8 & 76 & 10 & 3 & 11 & 56 & 33 & 11 \\
\hline 18 August & $88^{\circ} 05^{\prime} \mathrm{N}$ & $147^{\circ} 55^{\prime} \mathrm{E}$ & 310 & 0.03 & 23 & 0.8 & 86 & 3 & 0 & 11 & 77 & 13 & 10 \\
\hline
\end{tabular}




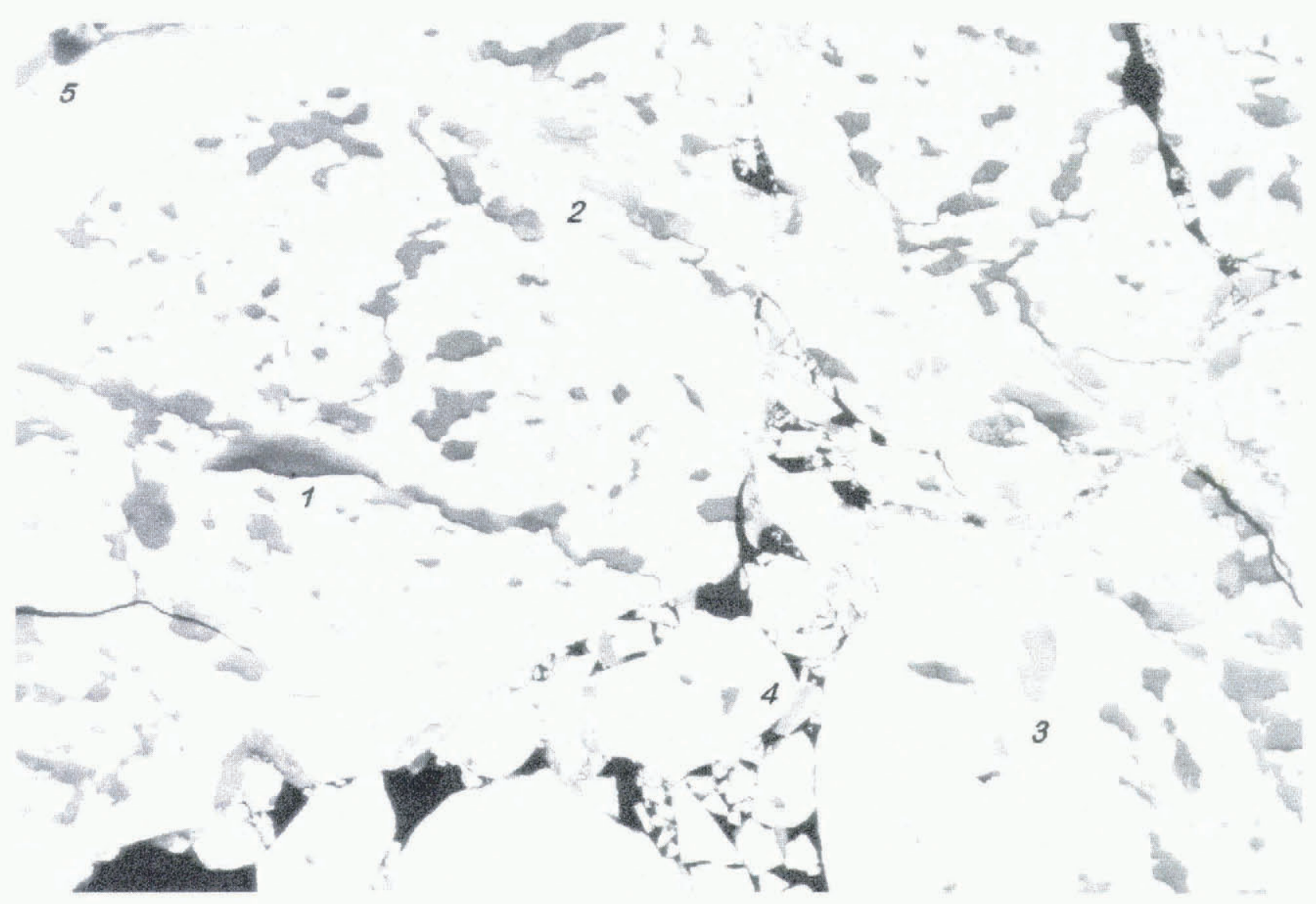

Fig. 1. A representative aerial photograph from the 31 July 1994 flight. The photograph was taken at an altitude of $660 \mathrm{~m}$ and has a horizontal scale of $440 \mathrm{~m}$. Some general features of melt ponds are illustrated: the largest ponds were several ponds connected by small tributaries; ridges often had ponds associated with them; pond color ranged from a light, whitish sky-blue to a dark bluegreen; there were pond-like features at the edges offloes; and a few ponds melted through and appeared black, like leads.

tuated from 5 to $20 \%$, exhibiting image-to-image variability even after adjusting for changes in the ice concentration. Combining results from all 160 images we found that there was $82 \%$ ice, $12 \%$ melt ponds and $6 \%$ leads in the $20.5 \mathrm{~km}^{2}$ area studied.

An understanding of the state of the variables of the ice cover on the aggregate scale is needed to link small-scale process-oriented models to large-scale climate models (Moritz and others, 1993). The aggregate scale can be thought of as the scale at which the sampling variability of

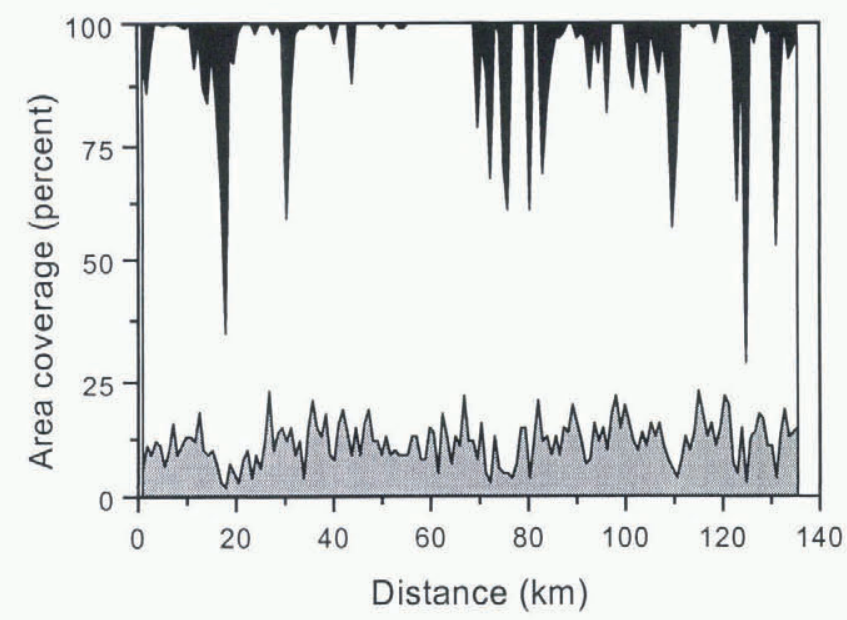

Fig. 2. Observations of the relative areas of ice, ponds and leads measured along the $142 \mathrm{~km}$-long flight path on 31 July 1994. The pond area is light gray, the ice area white, and the lead area black. a parameter is minimized (i.e. the scale large enough to give a representative sample). We can use the relative area results from the individual photographs to examine the aggregate scale for ice concentration and pond fraction. Since we have data on only one scale, we simulate larger areas by averaging results from adjacent photographs. It should be noted that the number of samples decreases as the area increases. The standard deviation of ice concentration and pond fraction as a function of sample area is plotted in Figure 3.

Both ice concentration and pond fraction exhibit a sharp initial drop-off, followed by a gradual tapering giving an aggregate scale dimension of roughly $2-3 \mathrm{~km}^{2}$. This result is somewhat tentative since we do not have enough areal coverage to extend the curves in Figure 3 to confirm that the standard deviation (std dev.) has reached a minimum value. Performing the same type of analysis on datasets from different locations and times of year would be valuable to investigate the variability of the aggregate-scale dimension, and to delineate between sampling variability and geophysical variability (Moritz and others, 1993).

We performed further analysis of the images to examine the characteristics of the melt ponds and leads in more detail. A subset of 131 photographs covering $17 \mathrm{~km}^{2}$ was processed to determine the number density, mean area, size distribution and shape factor for melt ponds. For this analysis, only ponds larger than $2 \mathrm{~m}^{2}$ were included; smaller ones were below our resolution threshold. Ponds were plentiful in this region, there being more than 28000 . Melt-pondnumber densities calculated from individual images showed considerable variability, ranging from 1000 to $3500 \mathrm{~km}^{2}$, with a mean of $1794 \mathrm{~km}^{-2}$ and a std dev. of 494 . 


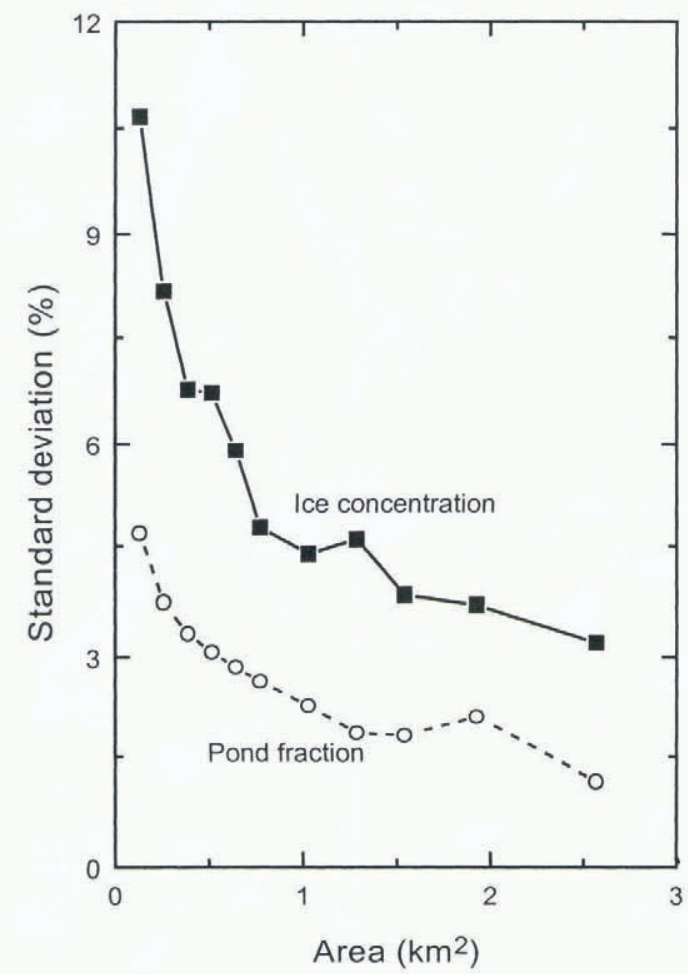

Fig. 3. Change in the standard deviation of ice concentration and pond fraction for progressively larger sample areas. Data are from 31 July 1994.

The size of the ponds also varied greatly, from $2 \mathrm{~m}^{2}$ ponds to ones as large as $8000 \mathrm{~m}^{2}$. The 28000 ponds measured had a mean and median pond area of $63 \mathrm{~m}^{2}$ and $14 \mathrm{~m}^{2}$. The cumulative probability distribution of pond area is plotted in Figure 4. Since a general description of pond area would be useful for modeling efforts, we applied data-fitting software (Jandel Scientific, 1994) to determine a functional relationship for the melt-pond size distribution. This size distribution is well fit (correlation coefficient $=0.999$ ) by a two-parameter cumulative lognormal distribution of the form

$$
\operatorname{CDF}(A)=\frac{1}{2} \operatorname{erfc}\left[\frac{-(\ln A-\mu)}{\sigma \sqrt{2}}\right],
$$

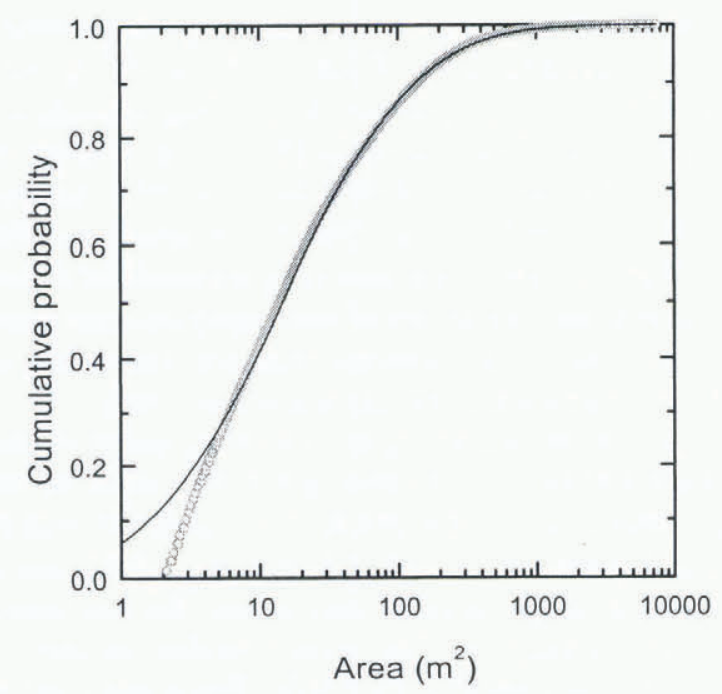

Fig. 4. Cumulative melt-pond size distribution for $>28000$ ponds taken from the 31 July 1994 photographs. The squares are the observations and the curve is the two parameter lognormal best-fit distribution. where $A$ is the area of the melt pond in $\left(\mathrm{m}^{2}\right)$. The two parameters, $\mu$ and $\sigma$, are the mean and std dev. of the variable $\ln (A)$ and have values of $\mu=14.7$ and $\sigma=1.73$. There is excellent agreement between the observed cumulative distribution and the lognormal fit, except for ponds smaller than $5 \mathrm{~m}^{2}$, where the lognormal fit predicts more ponds than observed. This difference is a direct result of the observations not including ponds smaller than $2 \mathrm{~m}^{2}$.

As is evident in Figure 1, the shapes of melt ponds vary considerably from round to elongated to intricate interconnected webs. We explored this variability in shape quantitatively by computing the circularity of each melt pond. The circularity is defined as $C=P^{2} / A$, where $P$ is the pond perimeter and $A$ the pond area. The smallest possible value of $C$ is $4 \pi$, corresponding to a circle. The value of $C$ increases as the shape deviates from a circle. For example, $C$ is equal to 16 for a square, 28 for a $5: 1$ rectangle and 484 for a 10:1 rectangle. The mean value of the circularity of all 28000 melt ponds was 35 and the median value was 27. These high values of circularity result from the elongated, and often complex, shapes of the ponds. There was no strong dependence between the circularity of a pond and its size, though there was a slight tendency for the biggest ponds to have high values of $C$. This is consistent with our observation that large melt ponds actually consist of a connected networks of ponds.

The altitude of the helicopter was too low to allow measurement of the floe-size distribution. However, it was possible to estimate the ice area, lead area and floc-lead perimeter. Theoretical studies state that the disposition of solar radiation absorbed in leads and the lateral melting of floes is dependent on the lead area and the floe perimeter (Perovich, 1983; Maykut and Perovich, 1987; Steele, 1992). In short, the greater the area of open water, the more solar radiation input to the ice-ocean system, and the greater the floe perimeter, the larger the fraction of that energy that contributes to lateral melting. Of the $20.5 \mathrm{~km}^{2}$ area that was analyzed from the 31 July 1994 photographs, $19.3 \mathrm{~km}^{2}$ was covered by ice floes and $1.2 \mathrm{~km}^{2}$ was open water. The total lead-ice floe perimeter was $178 \mathrm{~km}$.

Knowing the ice and lead area and the perimeter, estimates of the distribution of the solar radiation incident on the leads can be obtained from the results of previous modeling studies. According to the lateral-melting treatment of Maykut and Perovich (1987), a region of ice floes and open water can be considered to have an "effective" lead width equal to two times the lead area divided by the perimeter, or $15 \mathrm{~m}$ in this case. Their model, using meteorological forcing for the central Arctic during summer, predicts lateralmelt rates of approximately $5-7 \mathrm{~cm} \mathrm{~d}^{-1}$ for this case. Steele (1992) developed an ice-ocean model that included the effect of floe geometry on melting by considering an ice cover of circular floes with the same initial diameter. In such a treatment, the 31 July 1994 ice cover would be equivalent to approximately 137 floes of $422 \mathrm{~m}$ diameter. The Steele (1992) model predicts for this case that roughly $10 \%$ of the solar radiation deposited in leads contributes to lateral melting, giving melt rates of less than a few $\mathrm{cm} \mathrm{d}^{-1}$. The difference in predicted melt rates emphasizes the need for field observations of lateral melting and lead-ice interactions.

To provide a context for the 31 July 1994 observations, we analyzed photographs from flights on 13 and 18 August 1994 (Figure 5). The same analysis was performed, though it was for fewer images and consequently a smaller areal coverage. 


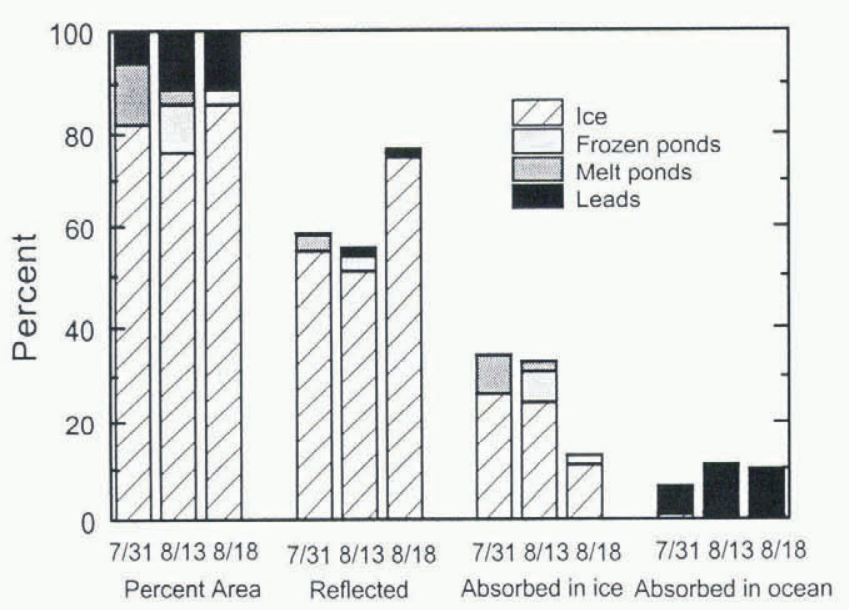

Fig. 5. Relative areas of ice and partitioning of incident solar radiation for 31 July, 13 August and 18 August 1994. The contribution from different surface conditions to the disposition of the solar radiation is also shown.

For these two flights, every tenth photograph was processed. The results are summarized in Table 1. Taken in sequence, the three flights moved northward towards the Pole, and progressed later in the season from summer to the onset of fall freeze-up. This transition is evident in the melt-pond results. The fractional pond coverage was similar between 31 July and 13 August, but by 13 August over half the pond area had begun to freeze. By 18 August, at $88^{\circ} \mathrm{N}$ there were no open melt ponds. Also, by 18 August the photographs indicate that the leads were beginning to freeze and there was a significant amount of young ice present. It is interesting to note that the smallest lead fraction $(6 \%)$ was on 31 July, even though that flight was the farthest south and the closest to the peak of the melt season. This illustrates the spatial variability present in the ice concentration. The melted-frozen pond fraction was significantly smaller for the 18 August flight. We believe that this low value was due, at least in part, to new snow covering that obscured frozen ponds and made them difficult to distinguish. This reaffirms the observation that as the surface begins to freeze and snow falls, the surface quickly becomes homogeneous.

An important application of observations of the surface state of ice cover is determining the partitioning of solar radiation incident on the ice cover from reflection to the atmosphere, absorption in the ice, and deposition in the ocean. The energy deposited in the ocean includes solar radiation absorbed in leads and what is transmitted through the ice. We were not able to make albedo measurements from the helicopter, and at present there is no effective way to make transmission measurements over a large area. We do, however, have surface-based measurements of ice thickness, physical properties and albedo, and aerial observations of the relative areas of ice, ponds and water. This information was combined with a two-stream radiative transfer model (Perovich, 1990) to estimate the partitioning of incident solar radiation for 31 July and 13 and 18 August 1994.

Though the ice cover for these cases was a variegated mixture of many different ice types, as a first step we assumed that it was composed of four components: bare or snow-covered ice, ponded ice, frozen ponds, and leads. This assumption is a simplification, since, as Figure 1 indicates, there is considerable variability in the albedo and optical properties even for different melt ponds. From the surface- based measurements we decided to assume that bare ice had optical properties similar to white ice Grenfell and Maykut, 1977) and was $2.5 \mathrm{~m}$ thick in all cases; ponded ice comprised $25 \mathrm{~cm}$ of meltwater over $223 \mathrm{~cm}$ of ice; and on 18 August there was a light dusting of snow. To get an areally averaged estimate of the distribution of the solar radiation, the values for the individual components were weighted by their relative area and combined. Because leads and melt ponds have small albedos, significantly more energy is input to the ice-ocean system by them than by a similar-sized area of bare ice. As Figure 5 indicates, even though leads are only a small portion of the total area $(\sim 10 \%)$, they account for most of the energy deposited in the ocean (Ebert and others, 1995). The presence of a thin, $2 \mathrm{~cm}$ layer of new snow on 18 August at $88^{\circ} \mathrm{N}$ increased the areally averaged albedo to 0.77 , and reduced by a factor of three the absorption of solar radiation in the ice. This sharp reduction in absorption, coupled with generally decreasing values of incident solar radiation, brought an abrupt end to the summer melt season.

\section{SUMMARY AND FUTURE WORK}

Aerial photographs were analyzed to determine the relative areas of ice, melt ponds and leads. Results from one flight taken during on 31 July 1994 at $76^{\circ} \mathrm{N}, 172^{\circ} \mathrm{W}$ showed that bare ice covered $82 \%$ of the total area, ponded ice $12 \%$, and open water $6 \%$. There was considerable variability in the area fractions of ice, ponds and leads on scales $<1 \mathrm{~km}^{2}$. Selecting sample areas $>2-3 \mathrm{~km}^{2}$ appeared to give representative values of ice concentration and pond fraction. Melt ponds were ubiquitous, with a number density of 1800 ponds $\mathrm{km}^{2}$. The melt ponds had a mean area of $62 \mathrm{~m}^{2}$, a median area of $14 \mathrm{~m}^{2}$, and a size distribution that was well fit by a cumulative lognormal distribution. Results from flights on 13 and 18 August showed that the ponds began to freeze further north.

Further work is needed to extend these results to larger spatial and temporal scales. The advantage of analyzing aerial photographs is that the surface state of the ice cover can be examined in detail and accurately. The main disadvantage is that considerable effort is required to survey a relatively small area. Ideally, photography missions should be flown at higher altitudes, allowing greater areal coverage. Using the same techniques and equipment, it would be possible to increase the altitude to $3000 \mathrm{~m}$, and consequently the areal coverage of a photograph to $2 \mathrm{~km}^{2}$, and still be able to resolve features such as melt ponds. However, the low clouds and fog so common in the Arctic during summer limit the opportunities for photography missions at higher altitudes.

Monitoring changes in the state of the ice cover at a particular location from the onset of melt until fall freeze-up would be very informative SHEBA Science Working Group, 1994). Investigating the temporal evolution of melt ponds and leads by combining aerial surveys with surfacebased observations could give significant insights into the melt processes of ice cover and the ice-albedo feedback. Aerial surveys could provide information on changes in the area fraction, and number and size of ponds and leads, while surface-based measurements could monitor pond depth, ablation and morphology, and lead heating and lateral ablation. 


\section{ACKNOWLEDGEMENTS}

The work was funded by the National Science Foundation, Office of Polar Programs: Arctic System Science (OPP9504311). The authors thank J. Mason, B. Elder and H. Bosworth for their able assistance with the image processing.

\section{REFERENCES}

Aagaard, K. and 10 others. 1996. U.S. Canadian researchers explore Arctic Ocean. EOS, $77(22), 209,213$.

Derksen, C., J. Piwowar and E. LeDrew. 1996. The quantification of sea ice melt features from low level aerial photographs. In IGARSS 966. Remote Sensing for a Sustainable Future, 27-31 May 1966, Lincoln, Nebraska. Proceedings. Vol. I. Pisacataway, NJ, Institute of Electrical and Electronics Engineers, $127-129$.

Ebert, E. E. and J. A. Curry. 1993. An intermediate one-dimensional thermodynamic sea ice model for investigating ice atmosphere inter-actions. f. Geophys. Res., 98 (C6), 10,085-10,109.

Ebert, E. E., J. L. Schramm andJ. A. Curry. 1995. Disposition of solar radiation in sea ice and the upper ocean. J. Geophys. Res., 100 (C8), 15,96515,975 .

Grenfell, T. C. and G. A. Maykut. 1977. The optical properties of ice and snow in the Arctic Basin. 7. Glaciol., 18 (80), 445-463.

Grenfell, T. C. and D. K. Perovich. 1984. Spectral albedos of sea ice and incident solar irradiance in the southern Beaufort Sea. 7. Geophys. Res., 89 C3), 3573-3580.

Ingram, W. J., C. A. Wilson and J. F. B. Mitchell. 1989. Modeling climate change: an assessment of sea ice and surface albedo feedbacks. 7 . Geophys. Res., 94 (D6), 8609-8622.

Jandell Scientific. 1994. Table curve user's manual. San Raphael, CA, Jandell Scientific.

Langleben, M. P. 1972. The decay of an annual cover of sea ice. 7. Glaciol.,
$11(63), 337-344$.

Manabe, S., R. J. Stouffer, M. J. Spelman and K. Bryan. 1991. Transient response of a coupled ocean-atmosphere model to gradual changes of atmospheric $\mathrm{CO}_{2}$. Part I: Annual mean response. 7. Climate, 4 8), 785-817.

Maykut, G. A. and M. G. McPhee. 1995. Solar heating of the Arctic mixed layer. J. Geophys. Res., $100(\mathrm{Cl} 2), 24,691-24,703$.

Maykut, G. A. and D. K. Perovich. 1987. The role of shortwave radiation in the summer decay of a sea ice cover. f. Geophys. Res., 92 (C7), 7032-7044.

Morassutti, M. P. and E. F. LeDrew. 1995. Mell pond dataset for use in sea-ice and climate-related studies. Waterloo, Ont., University of Waterloo. Institute for Space and Terrestrial Science. Earth-Observations Laboratory. (Tech. Rep. Ser ISTS-EOL-TR95-001.)

Moritz, R. E., J. A. Curry, A. S. Thorndike and N. Untersteiner, eds. 1993. SHEBA: a research program on the Surface Heat Budget of the Arctic Ocean. Seattle, WA, ARCSS OAII Science Management Office.

Optimas. 1995. Optimas 5, user guide and technical reference. Seattle, WA, Optimas.

Perovich, D.K. 1983. On the summer decay of a sea ice cover. (Ph.D. thesis, University of Washington.

Perovich, D. K. 1990. Theoretical estimates of light reflection and transmission by spatially complex and temporally varying sea ice covers. 7 . Geophys. Res., 95 (C6), 9557-9567.

Perovich, D. K. and G. A. Maykut. 1990. The treatment of shortwave radiation and open water in large-scale models of sea-ice decay. Ann. Glaciol., 14, $242-246$.

Rind, D., R. Healy, C. Parkinson and D. Martinson. 1995. The role of sea ice in $2 \times \mathrm{CO}_{2}$ climate model sensitivity. Part $\mathrm{I}$ : The total influence of seaice thickness and extent. 7. Climate, 8(3), 449-463.

Schramm, J. L. and J. A. Curry. 1994. Disposition of solar radiation in sea ice and the upper ocean. [Abstract.] EOS, 75 (16), Supplement, 210.

SHEBA Science Working Group. 1994. New program to research issues of global climate in the Arctic. EOS, 75 (22), 249, 253.

Stecle, M. 1992. Sea ice melting and floe geometry in a simple ice-ocean model. J. Geophys. Res., 97 (Cl1), 17,729-17,738.

Zubov, N.N. 1945. Lidy Arktiki [Arctic ice]. Moscow, Izdatel'stvo Glavsevmorputi. 